\title{
Waiting for the doctor to ask: influencers of lesbian, gay, and bisexual identity disclosure to healthcare providers
}

\author{
Nicole C. Hudak, ${ }^{1}$ Heather J. Carmack ${ }^{2}$ \\ ${ }^{1}$ School of Communication Studies, Ohio University, Athens, $\mathrm{OH} ;{ }^{2}$ Department of Communication Studies, University of Alabama, \\ Tuscaloosa, AL, USA
}

\begin{abstract}
Lesbian, gay, and bisexual (LGB) individuals encounter multiple barriers in healthcare, resulting in problematic care. Many LGB patients wrestle with whether to disclose their sexuality to healthcare providers. This article explored what influences LGB patients' decision to disclose their sexuality to healthcare providers. Guided by Communication Privacy Management theory, the authors conducted in-depth interviews with 20 LGB patients. LGB patients heavily relied on boundary management when negotiating the disclosure of their sexuality. The findings suggest several factors influence LGB patients' disclosure of sexuality: i) experience with family; ii) fear of gossip and connections; iii) concern for provider care refusal; iv) religion; v) age; and vi) level of trust with providers. Boundary turbulence can be created between patient and provider when there is uncertainty about if and when sexuality is considered private information. Additionally, a site of tension for LGB patients was their concern about providers sharing private information outside the clinic setting.
\end{abstract}

\section{Introduction}

Every ten years, Healthy People, a nation-wide initiative housed in the Office of Disease Prevention and Health

Correspondence: Nicole C. Hudak, School of Communication Studies, Schoonover Center Ohio University, Athens OH 457012979, USA.

Tel.: 740.593.4883 - Fax: 740.593.0459.

E-mail: nh017915@ohio.edu

Key words: Communication; Medical; Disclosure; Decision-making; Gay; Lesbian; Bisexual; Relationships; Patient-provider.

Contributions: $\mathrm{NCH}$ was the primary researcher and author. She conducted the interviews and wrote the manuscript. HJC served as $\mathrm{NCH}$ 's thesis advisor. She oversaw NCH data collection, analysis, and write-up. She edited the manuscript.

Conflict of interest: the authors declare no potential conflict of interest.

Funding: none.

Conference presentation: this manuscript is based on work from Ms. Hudak's master's thesis. A version of this manuscript was presented at the 2016 meeting of the Eastern Communication Association in Boston, MA.

Received for publication: 11 November 2017.

Revision received: 7 April 2018.

Accepted for publication: 8 April 2018.

This work is licensed under a Creative Commons Attribution NonCommercial 4.0 License (CC BY-NC 4.0).

CCopyright N.C. Hudak and H.J. Carmack, 2018

Licensee PAGEPress, Italy

Qualitative Research in Medicine \& Healthcare 2018; 2:20-29

doi:10.4081/qrmh.2018.7157
Promotion, issues a set of national health benchmarks for improving the health of people in the United States. The most recent iteration, Healthy People 2020, introduced a number of new objectives, including a focus on improving the safety, health, and well-being of lesbian, gay, bisexual, and trans (LGBT) individuals. According to the rationale for the new LGBT health objective, Eliminating $L G B T$ health disparities and enhancing efforts to improve $L G B T$ health are necessary to ensure that $L G B T$ individuals can lead long, healthy lives. ${ }^{1}$ Despite the inclusion of LGBT health in Healthy People 2020, little research on LGBT individuals' healthcare experiences has been conducted, particularly in health communication. In their study on men who have sex with men, Mimiaga, Goldhammer, Belanoff, Tetu, and Mayer explain, To date, most [studies] have reported on sexual orientation differences in the prevalence of psychiatric disorders, and a handful have explored other health issues (e.g., tobacco use, healthcare access, violence victimization, and chronic disease). ${ }^{2}$ These studies have been limiting because their focus is on how LGB bodies are less than heterosexual bodies. Further, current sexuality health literature more heavily features gay men, and gives significantly less attention to the health concerns of lesbian women. ${ }^{3}$ Additionally, when discussing gay men's health, a majority of the research specifically focuses on HIV/AIDS and/or sexually transmitted infections within the population. ${ }^{3,4}$ While this research is necessary, overly emphasizing sexually transmitted infections and HIV/AIDS can perpetuate stigma for the LGB community and is missing out on the larger experience of LGB healthcare. ${ }^{5}$

The limited health literature examining LGBT individuals and health has primarily focused on disorders and health outcomes. Although there is research examining how providers work with and care for LGBT patients, little com- 
munication research examines the communication practices between LGBT patients and providers. ${ }^{6-9}$ Little is known about the communication experiences between LGBT patients and providers. Assumptions of heteronormativity appear to negatively influence LGB individuals' health communication decisions, trust in providers, and disclosure of health information to providers. ${ }^{8}$ This may impact providers' ability to successfully care for LGBT patients because if a patient does not trust their provider, they may be less likely to provide important medical information. Patients' disclosure of their LGBT identity is important to counter heteronormativity in healthcare interactions. If LGBT patients never disclose their identity, providers can keep assuming that all of their patients are heterosexual. Previous qualitative health and communication researchers have studied the disclosure of various health illnesses to partners, family members, and providers. ${ }^{10-15}$ Some scholarship has started to look at disclosing sexuality in healthcare settings, but the researchers operated under the assumption that LGB patients will disclose their sexuality. ${ }^{9}$ While disclosure patterns are important, there also needs to be a discussion on how LGB patients choose to disclose their sexuality to their healthcare providers. By understanding patients' accounting of reasons for why they may or may not disclose, providers can work to facilitate open disclosures with their LGB patients.

This article is designed to serve as a step in addressing LGBT identity disclosure in healthcare by examining how LGB patients decide to reveal their sexual identity to their healthcare providers. Because the authors are interested in sexual identity disclosure, we are only focusing on LGB individuals. We begin by discussing LGB sexuality and identity disclosures, turning to Communication Privacy Management theory ${ }^{16}$ to offer a vocabulary to make sense of participants' experiences. After discussing our methodology, we identify the factors that influence LGB patients' disclosure decisions. Finally, we examine the implications of these findings on patient-provider communication.

\section{Disclosing lesbian-gay-bisexual sexuality}

The act of informing another person of one's personal information, such as sexual identity, is called disclosure. ${ }^{17,18}$ According to Bjorkman and Malterud ${ }^{17}$ disclosure can be medically relevant, even in unexpected ways. For example, a patient may require sleeping pills because of a recent breakup with a same-sex partner. In informing the provider, the patient may not want to use pronouns when referring to their partner. Even with the recognition that disclosure can be important, the choice to disclose is not always easy. This is particularly the case for lesbian women who feel that their sexuality is not apparent to their provider. ${ }^{17}$ In Austin's ${ }^{18}$ study, $40 \%$ of lesbian women chose not to disclose their sexuality to their doctor. Many lesbian women were anxious about whether to disclose their sexual orientation for fear that they would be mistreated or denied care. Without the patient disclosing, providers may offer inap- propriate or poor medical advice, diagnosis, and treatment options to LGB patients. For example, a provider recommending that a lesbian woman use birth control as a form of protected sex would be inappropriate and would not deal with sexual health in a way that is relevant to her life.

Sexuality disclosure does not solely rest with the LGB individual. Providers also have the opportunity to initiate conversations about sexuality. However, researchers have found that many doctors do not address their patients' sexuality. Kitts ${ }^{19}$ found that, although $64 \%$ of doctors did ask about the gender identities of their patients' partners, only $29 \%$ regularly talk about sexual orientation, $11 \%$ would discuss sexual attraction, and $8.5 \%$ talk about gender identity. These physicians identify a number of reasons for not talking about sexual orientation when discussing a patient's sexual history: $42 \%$ of the respondents said it was not significant, and $18 \%$ said they just forgot to discuss it. ${ }^{19}$ According to Kitt, ${ }^{19}$ providers were not clear or comfortable discussing patient's sexuality; only $44 \%$ of physicians agreed or strongly agreed that they had the skills to discuss sexual orientation, $51 \%$ disagreed or strongly disagreed that they had the skills to discuss sexual orientation, and $6 \%$ reported that they did not know if they had the skills to discuss sexual orientation, ${ }^{19}$ in part because many providers said they do not understand sexual orientation. Instead, physicians preferred patients bring up the topic or hoped that sexual orientation would become obvious during the medical interview or in conversations about STDs and birth control. ${ }^{19}$

Regardless of whether providers feel they have the tools to discuss sexual orientation, the inclusion of LGB discourse in healthcare from the provider perspective is lacking. Labig and Peterson ${ }^{20}$ found that very few doctors included questions about sexual orientation in their patient profile, and none of the doctors in their study posted LGB related literature in their offices. Furthermore, less than $20 \%$ of the physicians brought up medical conditions that were relevant to their patients' sexual practices. Healthcare providers avoid asking about sexual orientation for a number of reasons: ${ }^{20}$ they feel like they do not have time to discuss it, they feel uncomfortable about the issue, they have preconceived notions of sexuality, or they are unsure how to work with this minority group. ${ }^{20}$ These factors contribute to a don't ask, don't tell mentality: LGB individuals do not disclose their sexuality, and providers do not ask about sexuality during healthcare interactions.

Disclosing sexuality to a healthcare provider has consequences. The current belief about disclosure in a medical setting is that disclosure will only benefit a situation, while not disclosing only involves risks. ${ }^{21}$ However, there are both benefits and risks for disclosing sexual orientation. One benefit lesbian women identify about disclosing their sexual identity to their doctor is that they believe their doctors see them as a whole person, which creates a comfortable and inviting clinic atmosphere and helps them feel more connected with their doctor. ${ }^{17}$ Importantly, 
the impact of this positive atmosphere and satisfaction/ connection with their doctor is that it can lead to more preventative health screening. For lesbian women, disclosure is sometimes necessary for the correct diagnosis of gynecological and reproductive medical issues. ${ }^{17}$ For example, when a healthcare provider is inquiring about an issue that could be related to pregnancy, a lesbian woman may need to clarify that she only engages in sex with women, and cannot be pregnant. Finally, awareness of a patient's sexuality can allow for same-sex partners to be included in medical decision-making. ${ }^{17}$ The ability to disclose sexual orientation to providers can result in positive patient-provider relationships and patient satisfaction. For example, Labig and Peterson ${ }^{20}$ found that of LGB patients who disclosed their sexual orientation to their doctor, $86 \%$ felt comfortable with their primary care physician and did not feel the need to change providers.

Although disclosure is generally framed as a positive experience, there are still risks associated with disclosing sexuality to healthcare providers. LGB individuals fear basic discriminatory reactions from their doctors for disclosing their sexuality. The risks of disclosure can be very high for LGB individuals, including the refusal of healthcare (some states do not protect LGBTQ patients from care denial), intimidation by healthcare providers, breaches in confidentiality, patient embarrassment over having to disclose their sexuality, and fear of homophobic remarks. ${ }^{21,22}$ Even if a provider does not deny care, there is still a concern that LGB patients' sexuality disclosure will change the direction of the communication experience, with the focus moving from the medical reason for the visit to a singular focus on their sexuality. ${ }^{17}$

\section{Communication privacy management}

People are constantly making decisions about what private information to reveal, who should be allowed to have this information, and the ways to reveal this information. ${ }^{16}$ These tensions about private disclosure exist in every relationship because individuals express the need to share information, as well as protect themselves from certain information. Sandra Petronio's ${ }^{16}$ Communication Privacy Management (CPM) theory examines the tensions and dilemmas that exist in interpersonal relationships when considering the openness and privacy of information within a relationship. The fundamental premise of the theory is that individuals have a right to own and regulate who has access to their private information. ${ }^{16}$ CPM functions as a privacy management system, which identifies the ways that privacy boundaries are created and managed between individuals.

Privacy boundaries contain the information that individuals choose to label as private; these boundaries are not set up solely by an individual, but are constantly negotiated between individuals. In certain cases, private information is never shared with others. ${ }^{16}$ In other situations, boundaries shift, and this can lead to the opening or closing of bound- aries. ${ }^{16} \mathrm{~A}$ criterion of $\mathrm{CPM}$ is that private disclosures are viewed as dialectical. This means that they require conversation and negotiation. Disclosure is not an individual's decision. Rather, it is regulated by a metaphorical relational contract where both individuals balance an equal number of costs and rewards. ${ }^{16}$ For example, a patient deciding to disclose her sexual identity to a provider must take weigh the potential benefit of increased open communication with the potential for discrimination from a provider.

Health communication scholars have utilized CPM to study disclosure in patient-provider interactions. ${ }^{15,23}$ In healthcare settings, patients and providers become co-owners of private health information. Petronio and Sargent ${ }^{23}$ studied the privacy management strategies of nurses at critical care and emergency units at a hospital. Perspectives on privacy management seem to be different for the patient and for the provider, as nurses value their status as co-owners of private information. ${ }^{23}$ Nurses were expected to keep their patients' information confidential and appreciated their co-ownership status of that information. Carmack ${ }^{15}$ examined how nurses on a mobile health clinic navigated health disclosures in spaces where it was difficult to maintain privacy. The nurses of the mobile health clinic also valued their status as co-owners of patients' private information, and engineered unique ways to maintain that information. The same is true of disclosing sexual identity to health providers. Once a LGB patient discloses their sexual identity, the information is co-owned by the patient and provider. How this information is used by providers can impact the developing patient-provider relationship.

Disclosing sexuality to providers is not always easy and can impact both the LGB patient and healthcare provider. LGB individuals typically must decide if, how, and/or when they want to disclose their sexuality to their providers. This article draws on communication privacy management by looking at what influences LGB individuals' negotiation of privacy management with their healthcare providers about their sexuality. Given this complexity, the present article was guided by the research question: What influences $L G B$ patients' choice to disclose their sexuality to their healthcare providers?

\section{Methods}

\section{Participants}

The first author interviewed 20 LGB patients for this article. While the original call for participants asked for LGB, anyone who did not identify as heterosexual was able to participate. Participants were asked to provide a label for their sexual identity. They labeled themselves as gay $(n=9,45 \%)$, lesbian $(n=6,30 \%)$, bisexual $(n=2,10 \%)$, queer $(n=2 ; 10 \%)$, and pansexual $(n=1,5 \%)$. Participants' ages ranged from 22 to $51(M=32.9)$. Nineteen participants identified as Caucasian and one participant identified as African American. All of the participants lived in 
the United States. Nine participants were from the MidAtlantic region (45\%), four were from the Northeast (20\%), one was from the Pacific Northwest (5\%), one was from the Southeast (5\%), three were from the Midwest $(15 \%)$, and two were from the Southwest (10\%).

Recruitment began after the authors received university Institutional Research Board approval. The first author recruited participants using criterion sampling ${ }^{21}$ with a focus on LGB individuals. The distinction of what type of identity being disclosed is crucial when looking at healthcare because lesbian, gay, and bisexual individuals can choose whether to disclose their sexual orientation to their healthcare provider; however, if trans individuals want to receive adequate and appropriate healthcare, they have to disclose their trans identity. ${ }^{24}$ In order to respect the distinction between the two identities of sexual and gender identity, this article specifically focuses on sexual identity, or how individuals define their sexuality based on what gender to which they are sexually attracted to. Additionally, participants needed to have visited a healthcare provider to receive care within the past three years.

Participant recruiting occurred in two waves. First, an email call for participants was sent on a Mid-Atlantic university's LGBT faculty listserv and a call for participants was posted on the first author's Facebook page. In the second round of recruitment, another post was listed on the LGBT faculty listserv and on Facebook. The call for participants was also posted on CRTNET, the National Communication Association disciplinary listserv. Faculty listserv participants contacted the first author via email to set up in-person interviews. The participants recruited via Facebook and CRTNET contacted the first author via email to set up Skype or phone interviews.

\section{Data collection and analysis}

Qualitative interviewing was used as the primary method for this study. Qualitative interviewing allows researchers to understand a participant's experience, gather information about things or processes that cannot be observed in real time, and inquire about the past. ${ }^{25}$ Qualitative interviews provide the researcher with the opportunity for deeper and broader immersion into a subject area. ${ }^{25}$ In-depth interviews allow participants to provide rich, detailed answers and afford the interviewer the opportunity to ask follow-up questions. ${ }^{26,27}$

The interview protocol was semi-structured ${ }^{28}$ to ensure flexibility in adding additional, relevant questions for the participants. Questions in the protocol covered several different areas. The first set of questions was meant to gather demographic information about participants, including their age, where they were from, racial identity, and sexual identity. Participants were allowed to provide their own labels for their identities. A second set of questions were developed to obtain what type of healthcare (primary care, counseling, gynecology, etc.) the participants had sought, how often they sought out those types of healthcare, and how satisfied they were with their current healthcare. The third set of questions explored their sexuality disclosure experiences. Additionally, questions were asked about their opinions on how to discuss sexuality with healthcare providers. The final set of questions were about their romantic partners' interactions in healthcare settings.

Individual in-depth interviews were conducted in person $(n=13)$, on the phone $(n=5)$, and via Skype $(n=2)$. Interviews ranged from 35 to 61 minutes and were audio recorded. The recordings were transcribed verbatim, resulting in 312 single-spaced typed pages of data. Participants were assigned pseudonyms to maintain confidentiality.

The first author engaged in an inductive iterative method of data analysis. ${ }^{29}$ During the interview process, the first author made note of potential categories, allowing her to constantly compare and adapt categories as she conducted interviews. By comparing categories throughout the process, potential themes were being developed. Once all of the interviews were collected and transcribed, the first author read through the transcripts multiple times to gain a holistic understanding of the data. ${ }^{25}$ The first author open-coded the data by making notes of patterns in the transcripts; this involved identifying categories and crystalizing them into themes. Communication Privacy Management (CPM) emerged as a theoretical framework during the analysis process to help frame and make sense of the results. The first author consulted with the second author as a way to confirm the presence of themes and to support her analysis process. ${ }^{29}$ Direct quotations from participants were used to further demonstrate theoretical depth; ${ }^{29}$ quotations were selected for their forcefulness, repetition, and recurrence of ideas. ${ }^{30}$

\section{Results}

There was no single determinant of whether LGB individuals would disclose their sexuality to their provider. Multiple factors simultaneously influenced patients' decisions to reveal their sexual identity. These factors were related to past coming-out experiences, experiences with their healthcare providers, and their social demographics. Six decision factors emerged from the data: i) experience with family; ii) fear of gossip and connections; iii) concern for provider care refusal; iv) religion; v) age; and vi) level of trust with providers.

\section{Experience with family}

Participants strongly connected their family members' reactions to their coming out conversations to their decision to come out to their healthcare providers. If the participant did not have a positive coming out experience with their family, they were hesitant to discuss their sexual identity with the provider.

When Pete talked about his coming out experience with his parents, he said, It was an accident they found 
out. It's a pretty sad story...but they found out without my choosing and I didn't come out for a while after that as a result...Because of the negative reactions I have received in the past, it's kind of marred my openness personally. As Pete explained, this negative experience made him wary of potential negative reactions from providers. He would even lie about past sexual partners or sexual preferences in order to keep information about his sexual identity from his provider.

Grady also had a negative experience coming out to his family. Grady mentioned his family was connected to the local medical system and he connected most of the regional healthcare providers to his family. He stated, $I$ would worry that it could impact my healthcare, receiving or something, or I'd be known as the gay person at the hospital. He noted his family's connection to the hospital multiple times. He said, My family's somehow oddly connected to healthcare, which then influenced his choice to not come out to providers in that area.

For some participants, coming out to their parents or immediate family was positive; however, it can still make patients weary about disclosing to providers. Even the smallest amount of negativity can influence how a person feels someone is going to react to disclosure. Sonya's parents told her that they were okay with her identifying as a lesbian, but her extended family members may not be. Although Sonya's immediate family does not seem to have a problem with her sexuality, the hesitation to inform other family members seemed to effect how she thought her relationship with her medical provider would be affected by her coming out. She explained:

I do get a little bit of anxiety about them [providers] asking about sexual orientation. Well not so much sexual orientation, but asking about being sexually active or things like that. I'm a hard core people pleaser and I hate making people unhappy or making people awkward. So more times than not I'm nervous that telling someone about being gay. I understand there are people in the world who are not okay with it. I don't want to make things awkward. I don't want them to like not like me. Although Sonya stated that she was not extremely worried about disclosing her sexual orientation, she was still worried about potential negative reactions from providers about her same-sex practices and if providers would dislike her for those practices.

Those who had complicated coming out processes with their family showed similar hesitation in coming out to certain providers. For these participants, familial reactions to their coming out clearly impacted their decision to disclose their sexuality to healthcare providers.

\section{Fear of gossip and connections}

Several participants expressed that they were from small towns and had personal connections to the healthcare providers in those areas, increasing their hesitancy about disclosing their sexuality to providers. They were concerned that the providers might gossip about their sexual practices or sexual orientation to others in the area, potentially outing them in the community.

Grady mentioned, I come from a small town and there's only one doctor, so like, he doesn't need to know all my business. For Grady, it was not just about the small town, but his connection to his provider's son and how his provider was a friend of his parents. Grady further stated, $I$ like not talking sex with my main healthcare provider, 'cuz I'm friends with his son. We played soccer together when we were young and my parents went out to dinner with them every couple of months. This balancing community relationships and provider relationships prevented Grady from being open about his sexual practices with his general practitioner, and this was one of the reasons he sought out STI testing from another medical source.

Parental connections were frequently mentioned in interviews of participants who were in their twenties. Regardless of whether their parents knew about their sexual identity, participants were concerned about discussions of their sexual identity that were outside of their control. It did not matter whether or not the participant's parents already knew about their child's sexuality. Like Grady, Sonya was nervous about revealing her sexuality to her provider because of a provider-parent connection:

Well I felt really awkward about it because I mean even though my parents know, my parents go to the same doctor, so like, just because she knew the rest of my family, I was kind of a little nervous about saying [it] to her.

Participants were hesitant about revealing their sexuality to their providers because they were afraid that their providers would discuss their sexuality or sexual information with people that they knew outside of the healthcare setting.

\section{Concern for provider care refusal}

When talking about coming out to providers, some participants made it a point to come out to their providers while others disclosed because of providers' questions. However, for several participants, the topic of sexuality was never discussed because providers did not even bring up the topic of sexual health. Danny described a great connection he had with his general practitioner, of whom he had grown very fond. However, when asked if he had come out to his general practitioner, Danny realized that he had not. He explained, I guess I was kind of waiting for her to ask. Although Danny enjoyed the relationship he had with his provider, he did not feel as though he could bring up his sexuality without the provider creating space for that conversation. Danny struggled with why rationalizing why he did not come out to his provider and said he worried about ruining their good relationship. She felt like a friend, I didn't want to ruin that. I haven't always had a general physicians who were that welcoming and I didn't want that to suddenly 
stop. Because of Danny's uncertainty, he was therefore waiting for his provider to ask, providing him with a space to know that the conversation was allowed and would not ruin their current relationship.

Many participants believed their healthcare providers should initiate conversations about sexuality and sexual health. Like Danny, another participant, Garrett, stated, $I$ feel like if I was just seeing my general practitioner, it's not something that I talk about and I feel sort of, like, they could choose to bring it up if they wanted. Although Garrett did not express interest in discussing his sexual health or sexuality with his general practitioner, he later explained that even if he wanted to talk about it, he did not have the power to do so.

You don't really have the ability to just bring something up because you're not in that position. They're the doctor, they have their $M D$, they're treating you so they have the power in that situation to sort of choose what topics are relevant to your healthcare. Garrett's comment speaks directly to the power that providers have in the patient-provider relationship. Also, Garrett's words make evident how the provider may have the control over whether or not sexuality can be considered relevant to a person's healthcare. By the provider controlling whether sexual identity is relevant, $L G B$ patients remain uncertain about whether they have the ability to disclose that identity.

Another participant, Clifton, eventually came out to his general practitioner. But, during one of his earlier appointments when he sought medical advice about a concern related to a potential STI. Clifton explained, I went in to go see him and they [bumps] were nothing but he at no point asked about my sexual activity. If providers do not engage in conversations with their patients about sexual health or sexuality, the patients may not feel as though they are able to ask relevant questions or even feel comfortable bringing up the conversation on their own.

\section{Religion}

The religious beliefs of LGB patients and providers also influenced participants' decision to disclose their sexuality. In some cases, providers' religious beliefs were expressed in casual ways not related to sexuality. However, the tone of the comments concerned participants and impacted their decisions to disclose. Garrett visited a provider in his hometown who could administer his allergy medication, and he became uncomfortable with that provider because of how she expressed her religious beliefs during his appointments.

I have a tattoo of a Buddhist prayer and this most recent time she was like, oh why do you have that? And I said something about getting it when I was younger, because I didn't want to go into it with her. She was like, oh it was when you were younger and didn't know the right way, or something like that. It feels a little invalidating sometimes.
While the provider never spoke specifically against LGB individuals, Garrett felt that her religious influence was so strong that he could never broach that conversation with her. A history of religious intolerance of diverse sexual identities can then act as a barrier for disclosure between patient and provider because the LGB patient may fear discrimination based on their sexual identity.

Similarly, when Grady discussed his sexual practices with his provider, he stated, I think the doctor had like, a big cross or something necklace and I was like, 'Ehhh I'm not going to talk to you about this.' Even if a provider does not openly discuss his or her religious beliefs with patients, a simple religious symbol could deter LGB patients from disclosing their sexuality. Upon seeing the religious symbol or a provider expressing a religious belief, a LGB patient may then immediately distrust their provider and fear discrimination if they disclose their sexual identity.

Beyond identifying and expressing religious beliefs, healthcare providers may even alter their healthcare practices based on their religion, which was the case for Amelia. Amelia told the story of a past general practitioner she visited who had strict limitations on what type of medicine she would prescribe to her patients. She explained, I didn't realize until after I had started seeing her that she was Catholic, in a way that she wouldn't prescribe any sort of birth control and that sort of thing. Although Amelia did not need to receive birth control from her general practitioner, the provider made her wary. I was concerned that she wouldn't be able to really continue being my doctor and give me the best medical advice because it [religion] seemed to be such a barrier for her. Although many women are concerned about religion and birth control, Amelia was hesitant to discuss this with her provider because she was concerned about her reaction to her sexuality: I was concerned about the associated view she would have with [my] sexuality. A strong religious expression can either keep LGB individuals from disclosing sexuality and sexual practices or prevent them from seeing that provider altogether. By seeing a religious symbol or hearing a provider express their religious beliefs, LGB patients may then decide that it is best to not disclose their sexual identity for fear of discrimination based on those religious beliefs. They may also then decide to not go back to that specific provider because they do not want to continually fear discrimination.

\section{Age}

The participants varied greatly in age, and that difference demonstrated how age influenced their decision to disclose their sexuality to healthcare providers. Most of the participants in their twenties had only recently come out (within the past couple of years) and were more hesitant about discussing healthcare, and more specifically, how their sexuality related to the healthcare they received. On the other hand, the participants in their late thirties to 
early fifties were generally more open about their sexuality and communicated about their sexuality with greater ease. Throughout the interviews, participants who were younger would often express uncertainty about expressing sexual identity. In turn, those who were over the age of thirty, would express openness of their sexual identity.

Younger participants would often remove themselves from the conversation and discuss the discomfort of disclosing from an impersonal stance. In offering suggestions to healthcare providers, Pete, for instance, recommended that practitioners make sure they take the time to create the relationship, because young, scared, confused teenagers are not going to disclose that unless they feel comfortable. He did not want to discuss himself as a confused teenager. Instead, he displaced those feelings onto fictitious future patients. Pete took displacement a step further when he addressed those adults who have an easier time disclosing their sexuality: Adults are just more comfortable in themselves and their bodies and who they are; they've had time to go through those awkward phases. By taking an impersonal stance, Pete projected a discomfort in his own sexual identity and placed the reasoning on age by expressing how adults are more comfortable with themselves.

Similar to Pete, Sonya was not able to take on a diverse sexual identity with ease and displaced her feelings onto discussions of her girlfriend.

She has been out for a long time, she's, I'm trying to think, she's 24 and she has been out since she was, I think 19, so she's like a $110 \%$ comfortable in, like, openly saying it and doesn't think anything of it. Although Sonya would say things like, if someone asked I would say it, she separated herself from her partner by comparing herself to her current partner. By talking about how her partner is extremely comfortable and open, she positions herself in a juxtaposition where she is not like her partner, expressing potential discomfort.

Younger LGB individuals may have recently come out for the first time, and therefore, may be getting used to their newfound identity, creating a discomfort in openly disclosing their sexuality. Participants who had been out for longer periods of time explained that when they were younger, they would not have been as comfortable as they are now discussing sexuality. When talking about disclosing to healthcare providers, Jeannette, for instance, said, I don't think I would have done that as a younger person as much as I was willing to do it as a more adult person. Although Jeannette suggested some lingering hesitations, she still mentioned how her maturity aided her in her ability to disclose her sexuality to her provider. Kent further explained, I think I certainly would have...in my younger days, if a doctor had ever said anything, absolutely I would have lied. Even if asked by providers, younger LGB individuals may go beyond simply refusing to disclose. They may actively lie to providers because of their discomfort in their sexuality.

\section{Level of trust with providers}

Another significant factor concerning whether patients were willing to disclose sexuality to their providers relates to whether they trusted their providers. Some of the participants explained that they needed to have established a rapport with their provider in order to feel comfortable disclosing their sexuality to them. Disclosing sexuality is a vulnerable communication experience, and as Hannah and Pete emphasize, they need to feel a sense of trust in order to be vulnerable and open with their providers. Hannah explained, If it was someone I didn't feel was very trustworthy, or gave me a weird vibe, or if maybe it was a man, I don't know if I would have been as comfortable doing that. Pete, who was already hesitant in coming out because of his experience with his parents, said, I definitely wasn't feeling the trust with my doctor to tell him that I identified as bisexual.

For participants, trust was associated with how welcomed they felt at the provider's office. To these LGB patients, trust could not be established if they did not feel they belonged in the healthcare space. According to Greta, if they [LGB individuals] don't sense a welcoming atmosphere, they're generally not going to disclose themselves if given the chance to their provider. Whenever a positive rapport was established between a LGB individual and provider, there was a sense of trust and comfort that allowed for them to be open and honest about their sexuality. Tim said, The comfort level that I have just in that particular environment, like I don't have to hide, I don't have to make things up, pretend I'm somebody I'm not.

\section{Discussion}

This study is concerned with the factors that influence LGB patients' sexuality disclosure to their providers. Participants identified several influencers that relate to the negotiation of communication boundaries. Participants were heavily influenced by past experiences they had communicating about their sexuality, perceived bias, and the patient-provider relationship. Interestingly, the data reveal that, as LGB patients age, they are more confident about disclosing their sexual identities to their providers. Perhaps they become more comfortable over time because they have just had to disclose their sexual identity more often. After a while, the act of disclosure becomes easier because there have been more experiences in the types of disclosure.

First, LGB individuals may not have been hesitant about disclosing their sexuality because they see sexual identity as public information. However, they may have been uncertain about how their healthcare provider felt about receiving that information, especially if providers treat sexuality as private information. Petronio ${ }^{16}$ explained that for there to be boundary management, the person revealing the information has to define that information as 
private. The tension here lies in whether sexuality is private or public information. While most of the participants viewed their sexuality as public information, it is possible they believe healthcare providers viewed sexuality as private information (in other words, as information that does not need to be disclosed). CPM does not discuss what happens when there is a misunderstanding about whether information is private. Privacy is often violated because the owner of the information believes it is private. In this case, the person who owns the information (the LGB patient) does not see his or her sexuality as private. But, what happens when patients enter a healthcare setting with information they see as public and open for discussion? How should patients and providers coordinate the disclosure of that information?

Second, since boundary rules cannot be established by a singular person, ${ }^{16}$ LGB patients may have been waiting for providers to initiate a conversation about sexuality or the gender(s) of their sexual partner(s), and that is why some of them did not disclose on their own. Whereas LGB individuals may take control and establish communication boundary rules in other situations, the power dynamics present in patient-provider relationships serve an important role in the interaction. Certain participants openly recognized that their providers had the power in their appointments to determine and drive the healthcare conversation, including the disclosure, or lack of disclosure of sexual identity. Participants expressed that they did not feel as though they had the ability to assert themselves in the doctor-patient relationship in order to initiate a conversation about their sexuality. Some patients feared their doctor would discriminate against them, or feared that they would simply ruin the relationship that they had already established with their provider. If providers do not bring up sexuality, it may signal to LGB patients that their providers are uncomfortable with or not knowledgeable about the topic. The lack of clarity about who can, and should initiate these conversations create boundary turbulence, which occurs when there is uncertainty about communication expectations. ${ }^{16}$ This uncertainty is compounded by power differences in the patient-provider relationship. LGB patients clearly indicated they believed providers should start the conversation. If providers remain silent (because of lack of knowledge or comfort with the topic), providers do not create the communicative space to be able to discuss important health information with their patients.

Successfully negotiating disclosure factors does not mean that LGB patients will ultimately disclose their sexuality to providers. Although some of the participants disclosed their sexual identity to their providers, many chose to not disclose, even in the face of it impacting their healthcare experience. Those who did not share their sexuality may not have trusted their provider to be a co-owner of the information. ${ }^{16}$ As we have discussed in this study, mistrust was a primary factor for participants worried about personal connections between their healthcare providers and other family and friends. Petronio ${ }^{16}$ argues, if people feel like there is too great of a risk in disclosing private information, they will ultimately choose not to disclose that information. Of course, Health Insurance Portability and Accountability Act (HIPAA) regulations prevent providers from disclosing information with others and none of the participants said that their providers violated HIPAA. However, the perceived fear of that communication violation was enough to prevent disclosure. Past communication research has found that perceived disclosure violations can negatively impact patients' desire to continue seeking care. ${ }^{31}$ This perceived communication violation could contribute to an increased disparity in LGB healthcare.

This article identified two ways in which LGB individuals chose not to disclose: lying and manipulating language. If a provider asked about a partner's sexual history, an LGB person who did not want to share that information simply lied rather than disclose their sexuality. Participants also mentioned how it was possible to avoid the disclosure of their sexuality by using gender-neutral language to avoid acknowledging the truth. By not disclosing their sexuality, there was no need to worry about exchanging private information, having their providers being co-owners, or be concerned that providers were violating HIPAA by sharing that information with others. ${ }^{16}$ However, patients should have no need to worry about sharing private information with providers because providers are not allowed to share private information with others. Distrust in revealing sexual identity to providers potentially signals a need for more education for patients and providers - HIPAA education for patients to know providers are not disclosing their information and communication training for providers to help alleviate patients' fears. Any patient, regardless of sexuality, should not have to worry about a provider discussing their healthcare outside of medical appointments.

\section{Conclusions}

Although this study sheds light on LGB communication in healthcare, some limitations must be noted. To start, the sample did not have much diversity. First, not all sexual identities were represented. While there were a variety of sexual identities represented in this study, including queer and pansexual, gay men comprised the majority of the participants. A larger sampling could lead to more commonalities and differences amongst different sexual identities. Furthermore, there was a lack of racial diversity in the sample. Only one of the participants identifies as African-American. More racial and ethnic diversity would allow researchers to discuss issues of intersectionality related to LGB healthcare. The authors also did not ask for participants' socioeconomic status. Having access to a healthcare provider is a form of privilege often not granted to those of a lower socioeconomic status and could be an important factor. 
Second, although the participant call went out on a number of social media platforms, the participants drawn to this study were all university students, staff, or faculty. Being part of a university system may provide these participants more resources and access to healthcare. LGB patients who do not attend or work in these kinds of privileged settings or positions may not be able to not seek care from a healthcare provider on a regular basis. Their experiences are missing from this study, and need to be examined.

Third, only the perspectives of LGB patients are presented in this study. While LGB patients' perspectives are incredibly important, as they are marginalized, including provider perspectives could allow us to paint a more complex picture of how disclosure of sexuality is navigated in the patient-provider relationship and the possible communication barriers that occur. Healthcare providers may not be aware of communication barriers, and their perspectives could help to identify communication strategies to improve LGB patients' healthcare experiences. Along with inquiring about the awareness of LGB patients, researchers should examine providers' knowledge, education, and training about treating LGB patients and how they view the importance of patients disclosing their sexuality.

Finally, gay and bisexual men consistently brought up the need to be tested for STIs and HIV, yet the women rarely mentioned the topic. Beyond examining the interaction between healthcare providers and LGB patients, future research should examine how lesbian and bisexual women communicate about STIs, the knowledge lesbian and bisexual women have of STIs, and how they negotiate safe sex with their sexual partners. Understanding their perspectives could create a better understanding of lesbian and bisexual women's knowledge of STIs so that they can communicate relevant safe-sex information to their lesbian and bisexual women patients.

As the authors write this article, Healthy People 2020 is coming to a close. The Advisory Committee on National Health Promotion and Disease Prevention Objectives for 2030 is currently writing the objectives, directions, and outcomes for Healthy People 2030. We hope LGBT health is again identified as a priority objective. Disclosure of sexual identity is just one part of the picture of LGBT healthcare, but also an important aspect. Researchers need to continue studying this community to help in the fight for health equity and equality for LGBT individuals. As the findings from this article show, there is still work to be done to improve the patient-provider communication experiences of LGB patients and it will take patients, providers, advocates, educators, and legislators to make this happen.

\section{References}

1. Healthy People 2020. Lesbian, gay, bisexual and transgender health. United States Department of Health and Human Services. Washington, DC: USDHHS; 2013. Available from: http://www.healthypeople.gov/2020/topicsobjectives2020/o verview.aspx?topicid=25. Accessed: May 2015.

2. Mimiaga MJ, Goldhammer H, Belanoff $\mathrm{C}$, et al. Men who have sex with men: perceptions about sexual risk, HIV and sexually transmitted disease testing, and provider communication. Sex Transm Dis 2007;34:113-9.

3. Kuyper L, Vanwesenbeek I. Examining sexual health differences between lesbian, gay, bisexual, and heterosexual adults: the role of sociodemographics, sexual behavior characteristics, and minority stress. J Sex Res 2011;48:263-74.

4. McNair R. Outing lesbian health in medical education. Women Health 2003;4:89-103.

5. Hudak N. 'Do you have to ask me one more time?': communicating heterosexism in healthcare. Competitive paper presented at the NCA, Philadelphia, PA; 2016.

6. Goins ES, Pye D. Check the box that best describes you: reflexivity managing theory and praxis in LGBTQ health communication research. Health Commun 2012;28;397-407.

7. Hudak N, Bates BR. In pursuit of 'queer-friendly' healthcare: an interview study of how queer individuals select care providers. Health Commun 2018;1-7.

8. Utamsingh PD, Smart Richman L, Martin JL, et al. Heteronormativity and practitioner-patient interaction. Health Commun 2016;31:566-74.

9. Venetis, MK, Meyerson, BE, Friley, BL, et al. Characterizing sexual orientation disclosure to heatlh care providers: lesbian, gay, and bisexual perspectives. Health Commun 2017;32;578-86.

10. Greene K, Magsamen-Conrad K, Venetis MK, et al. Assessing health diagnosis disclosure decisions in relationships: testing the disclosure decision-making model. Health Commun 2012;27:356-68.

11. Neville Miller A, Rubin DL. Factors leading to self-disclosure of a positive HIV diagnosis in Nairobi, Kenya. Qual Health Res 2007;17:586-98.

12. Smith RA, Hernandez R, Catona D. Investigating initial disclosures and reactions to unexpected, positive HPV diagnosis. West J Commun 2014;78:426-40.

13. Broekema K, Weber KM. Disclosures of cystic fibrosis-related information to romantic partners. Qual Health Res 2017;27:1575-85.

14. Qiao S, Li X, Staunton B. Practice and perception of parental HIV disclosure to children in Beijing, China. Qual Health Res 2014;24:1276-86.

15. Carmack HJ. 'What happens on the van, stays on the van': the (re)structuring of privacy and disclosure scripts on an Appalachian mobile health clinic. Qual Health Res 2010;20: 1393-1405.

16. Petronio S. Boundaries of privacy: dialectics of disclosure. Albany, NY: State University of New York Press; 2002.

17. Bjorkman M, Malterud K. Being lesbian - does the doctor need to know?: a qualitative study about the significance of disclosure in general practice. Scand J Prim Health Care 2007; $25: 58-62$.

18. Austin EL. Sexual orientation disclosure to health care providers among urban and non-urban southern lesbians. Women Health 2013;53:41-55.

19. Kitts RL. Barriers to optimal care between physicians and lesbian, gay, bisexual, transgender, and questioning adolescent patients. J Homosex 2010:57:730-47.

20. Labig CE, Peterson TO. Sexual minorities and selection of a primary care physician in a Midwestern U.S. city. J Ho$\operatorname{mosex} 2006 ; 51: 1-5$. 
21. Fish J. Heterosexism in health and social care. New York, NY: Palgrave Macmillan; 2006.

22. Mayer KH, Bradford JB, Stall R, et al. Sexual and gender minority health: what we know and what needs to be done. Am J Pub Health 2008;98:989-95.

23. Petronio S, Sargent J. Disclosure predicaments arising during the course of patient care: nurses' privacy management. Health Commun 2011;26:255-66.

24. Parkhill AL, Mathews JL, Fearing S, Gainsburg J. A transgender health care panel discussion in a required diversity course. Am J Pharm Educ 2014;78:1-7.

25. Lindlof TR, Taylor BC. Qualitative communication research methods. 3rd ed. Thousand Oaks, CA: Sage Publications; 2011.

26. Keyton J. Communication research: asking questions, find- ing answers. 2nd ed. New York, NY: McGraw-Hill; 2006.

27. Johnson JM. In-depth interviewing. In: Gubrium JF, Holstein JA, eds. Handbook of interview research: context and method. Thousand Oaks, CA: Sage; 2002. pp 103-119.

28. Creswell JW. Research designs: qualitative, quantitative, and mixed methods approaches. 4th ed. Thousand Oaks, CA: Sage Publications; 2014.

29. Tracy SJ. Qualitative quality: eight 'big-tent' criteria for excellent qualitative research. Qual Inq 2010;16:837-51. Available from: http://qix.sagepub.com/.

30. Owen WF. Interpretive themes in relational communication. Q J Speech 1984;70:274-87.

31. Sankar P, Mora S, Merz JF, Jones NL. Patient perspectives of medical confidentiality: a review of literature. J Gen Intern Med 2003;18:659-69. 